\title{
Analysis of Ostwald ripening in Ni-rich Ni-Ti alloys by diffusion couples
}

\author{
C G GARAY-REYES ${ }^{\mathrm{a}, *}$, F HERNÁNDEZ-SANTIAGO ${ }^{\mathrm{b}}, \mathrm{N}^{\mathrm{N}}$ CAYETANO-CASTRO $^{\mathrm{c}}$, \\ R MARTÍNEZ-SÁNCHEZ ${ }^{d}$, J L HERNÁNDEZ-RIVERA ${ }^{d}$, H J DORANTES-ROSALES ${ }^{\mathrm{e}}$ and \\ J J CRUZ-RIVERA ${ }^{\mathrm{a}}$ \\ ${ }^{a}$ Universidad Autónoma de San Luis Potosí, Instituto de Metalurgia, Sierra leona 550, Col. Lomas 2 sección, \\ 78210 SLP, México \\ ${ }^{b}$ Instituto Politécnico Nacional, ESIME-AZC, Av. de las Granjas 682, Col. Sta. Catarina, 02550 DF, México \\ 'Instituto Potosino de Investigación Científica y Tecnológica, División de Materiales Avanzados, \\ camino a la Presa San José 2055, Col. Lomas 4 sección, 78216 SLP, México \\ ${ }^{\mathrm{d} C e n t r o ~ d e ~ I n v e s t i g a c i o ́ n ~ d e ~ M a t e r i a l e s ~ A v a n z a d o s ~(C I M A V), ~ L a b o r a t o r i o ~ N a c i o n a l ~ d e ~ N a n o t e c n o l o g i ́ a, ~}$ \\ Miguel de Cervantes 120, ZC 311109, Chihuahua, México \\ e Instituto Politécnico Nacional, ESIQIE-DIM, 118-556 DF, México
}

MS received 26 August 2013; revised 30 November 2013

\begin{abstract}
The coarsening kinetics of $\gamma^{\prime}$ precipitates in Ni-rich Ni-Ti alloys are studied using a Ni-11.5 wt\% $\mathrm{Ti}$ and pure $\mathrm{Ni}$ diffusion couple. The formed concentration gradient allowed to study the aging process at $1023 \mathrm{~K}\left(750{ }^{\circ} \mathrm{C}\right)$ in Ni-rich Ni-Ti alloys with $\mathrm{Ti}$ content from 8.62 to $11.15 \mathrm{wt} \% \mathrm{Ti}$. In general, during the coarsening of $\gamma^{\prime}$ precipitates, the experimental coarsening kinetics do not fit well to the LSW or TIDC theoretical models and anomalous behaviour of coarsening rate constant $\left(k_{\mathrm{r}}\right)$ associated with $\gamma^{\prime}$ volumefraction is confirmed at high values.
\end{abstract}

Keywords. Diffusion couple; nickel-based alloys; $\gamma^{\prime}$ precipitates coarsening; TIDC theory; LSW theory; anomalous coarsening.

\section{Introduction}

The rich-Ni Ni-Ti system has been studied by many researchers who used many different techniques including magnetic measurements, X-ray diffraction (XRD), transmission electron microscopy (TEM), high-resolution TEM (HR-TEM), atom-probe field-ion microscopy (APFIM) and small-angle neutron scattering (SANS) (Taylor and Floyd 1952, 1953; Bagariatskii and Tiapkin 1957, 1961; Bücle et al 1959; Ben Israel and Fine 1963; Sass et al 1967; Saito and Watanabe 1969; Ardell 1970; Sinclair et al 1974; Laughlin 1976; Hashimoto and Tsujimoto 1978; Grune 1988; Cerri et al 1990; Vyskocil et al 1997; Bucher et al 2002; Kompatscher et al 2003). The above mentioned studies have concluded that cuboidal-type $\gamma^{\prime}$ precipitates ( $\mathrm{L} 1_{2}$ structure) aligned along $\langle 100\rangle$ directions with faces parallel to $\{100\}$ planes are the cause of hardening, but these precipitates coarsen at high-temperatures and prolonged service times causing loss of coherency and eventually affect the mechanical properties.

Coarsening is theoretically described by the model proposed by Lifshitz-Slyozov and Wagner (LSW theory)

*Author for correspondence (garay_820123@hotmail.com)
(Lifshitz and Slyozov 1961; Wagner 1961) which predicts (for diffusion-controlled coarsening) precipitates dispersed in a fluid matrix (volume-fraction of the precipitates $\left(f_{\mathrm{v}}\right)$ close to zero) that coarsen according to the relationship, $r^{3}=k_{\mathrm{r}} t$, where $r$ is the average radius of the precipitate, $t$ the aging time and $k_{\mathrm{r}}$ the coarsening rate constant. There exist some modifications to the LSW theory (Ardell 1972; Brailsford and Wynblatt 1979; Davies et al 1980; Tsumaraya and Miyata 1983; Marqusee and Rose 1984; Tokuyama and Kawasaki 1984; Voorhees and Glicksman $1984 \mathrm{a}, \mathrm{b})$ that take into account the effect of $f_{\mathrm{v}}, k_{\mathrm{r}}=k_{\mathrm{r}\left(f_{\mathrm{v}}\right)}$, these theories differed to LSW theory in a broader particle size distribution (PSD) and in a increase of $k_{\mathrm{r}}$ in function of increasing $f_{\mathrm{v}}$, however, it was evident that a linear relationship between the cube of the average radius and aging time similar to LSW theory. A different behaviour of $k_{\mathrm{r}}$ during the coarsening has been reported for Ni-based alloys with elastic strains, where $k_{\mathrm{r}}$ decreases in function of increasing $f_{\mathrm{v}}$ (at low volume-fraction), which is known as anomalous coarsening (Ardell 1990; Maheshwari and Ardell 1992; Cho and Ardell 1998; Kim and Ardell 2000, 2003, 2004). Taking into account the anomalous coarsening a more realistic model, where coarsening is independent $f_{\mathrm{v}}$, has been developed by Ardell and Ozolins (2005) and Ardell (2010) and is called trans-interface diffusion- 


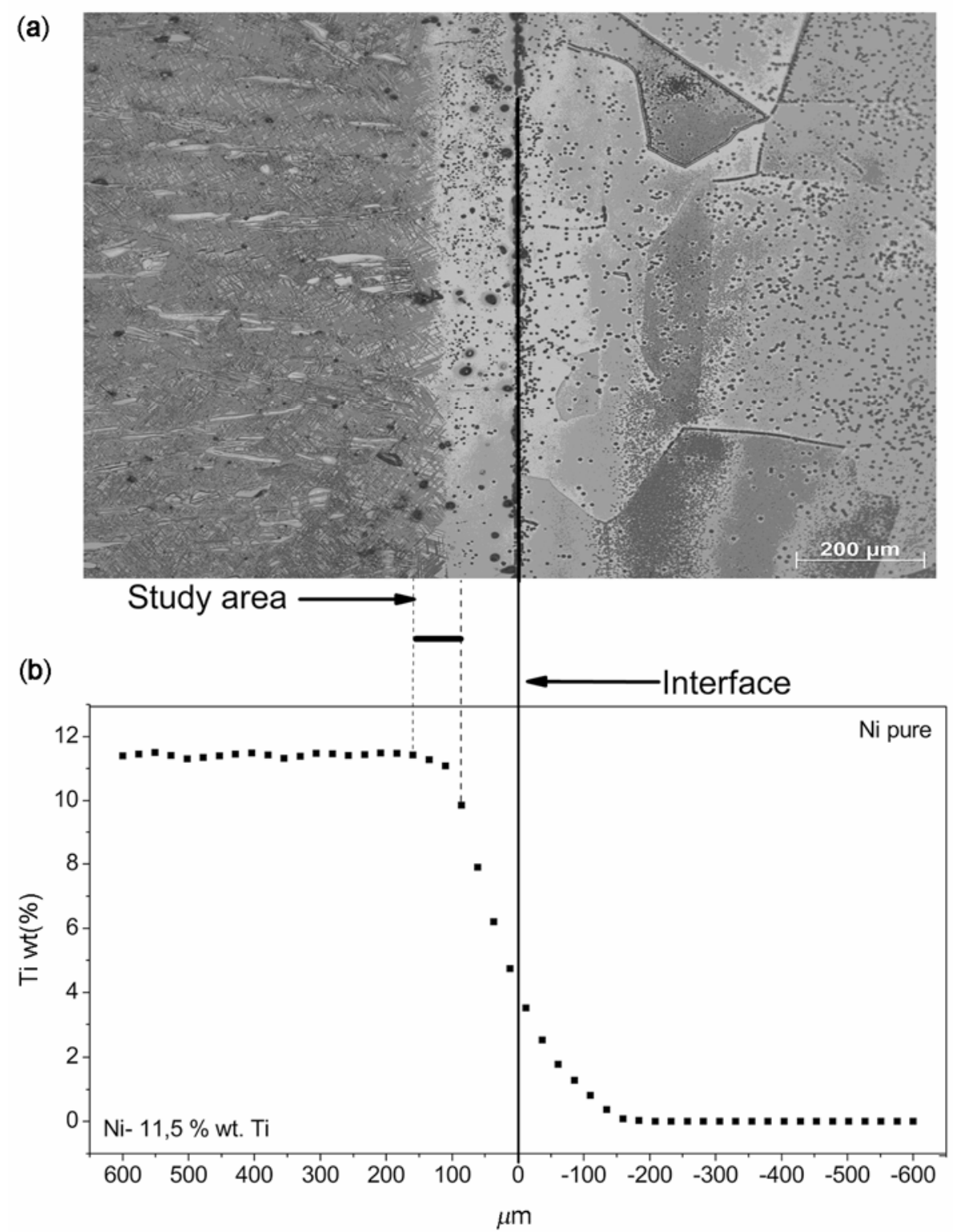

Figure 1. (a) It shows the $\mathrm{Ni} / \mathrm{Ni}-11.5 \mathrm{wt} \% \mathrm{Ti}$ diffusion couple after diffusion heat treatment at $1473 \mathrm{~K}\left(1200{ }^{\circ} \mathrm{C}\right)$ for $28 \mathrm{~h}$ and aging treatment at $1023 \mathrm{~K}\left(750{ }^{\circ} \mathrm{C}\right)$ for $5000 \mathrm{~min}$. (b) It shows the concentration profile of $\mathrm{Ti}$ and the existence of a concentration gradient.

controlled (TIDC) theory. A rate law of type $\langle r\rangle^{n} \approx k_{\mathrm{I}} t$ is predicted by the TIDC theory, where $n$ is related to the width of the interface matrix/precipitate. For the coarsening of $\gamma^{\prime}$ precipitates in $\mathrm{Ni}-\mathrm{Ti}$ system it was used as an exponent $n=2.375$ (Ardell et al 2006), but a subsequent study evidenced that the best fit with an exponent $n=2 \cdot 281$ (Ardell 2011).

On the other hand, Miyazaki (2012) proposed a characterization method to study the precipitation process in binary alloys, called the macroscopic concentration gradient (MCG) method. This method enables to determine solubility limits and phase equilibrium; it is based on the microstructural observation of different composition alloys formed by a continuous concentration gradient, which can be created in a specimen by diffusion coupling, imperfect arc melting of sandwiched metals, imperfect homogenization of coarse precipitates, etc. ContrerasPiedras et al (2012), based on the MCG method, used diffusion couples to analyse the precipitation in Fe-rich $\mathrm{Fe}-\mathrm{Ni}-\mathrm{Al}$ alloys and demonstrated the effectiveness of the method to study the coarsening process.

Thus, the purpose of this work is to analyse the coarsening of $\gamma^{\prime}$ precipitates in Ni-rich Ni-Ti alloys using diffusion couples in order to determine which model, LSW or 
Region $/ \mathrm{Ti} w \mathrm{w} \%$

$R 1 / 8.62 \pm 0.28$

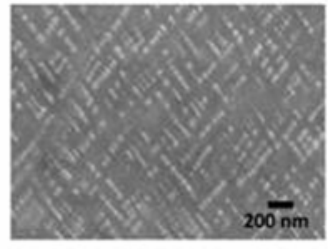

$R 2 / 9.49 \pm 0.14$

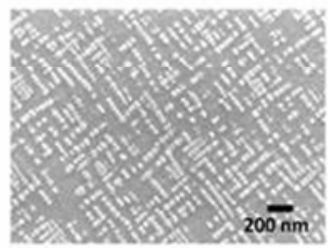

$R 3 / 10.60 \pm 0.19$

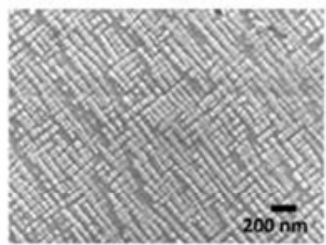

$R 4 / 11.15 \pm 0.28$

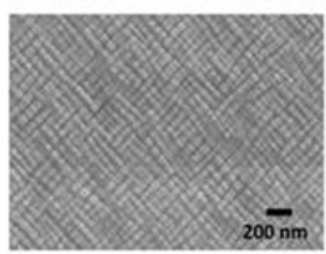

250
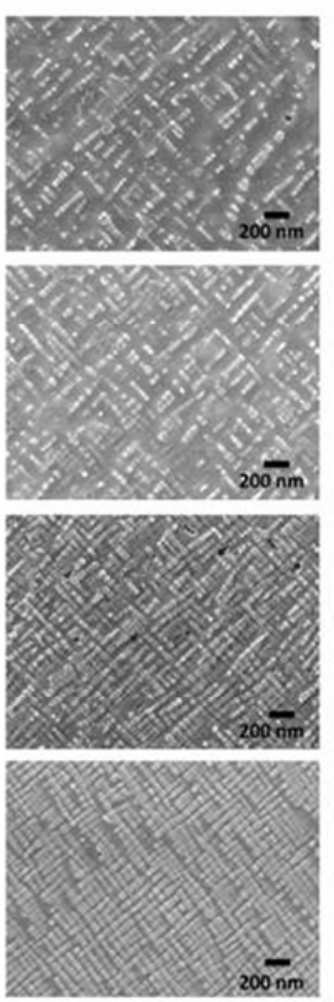

500
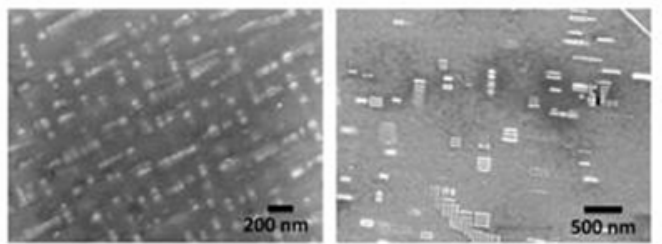

Volume fraction

(\%)

5.8
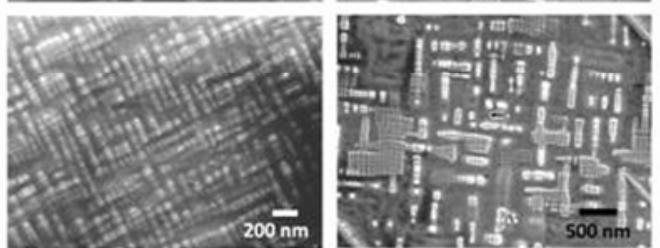

21
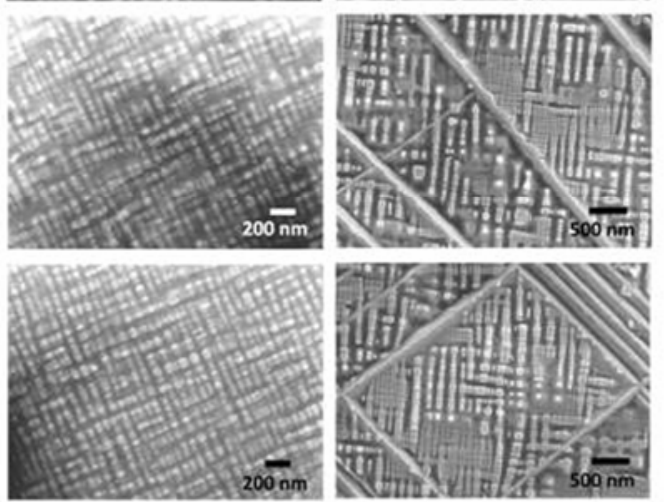

2500

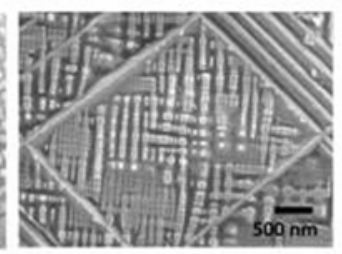

5000

Figure 2. HR-SEM micrographs show the microstructural evolution for the regions R1, R2, R3 and R4 after aging at $1023 \mathrm{~K}$ $\left(750{ }^{\circ} \mathrm{C}\right)$ for different times.

Table 1. Chemical composition and volume-fraction (determined from the coherent solvus (Rastogi and Ardell 1969)) in the four regions, R1, R2, R3 and R4.

\begin{tabular}{lcc}
\hline Region & Ti $(w t \%)$ & Volume-fraction $\left(f_{\mathrm{v}}\right)(\%)$ \\
\hline R1 & $8 \cdot 62 \pm 0 \cdot 28$ & $5 \cdot 8$ \\
R2 & $9 \cdot 49 \pm 0 \cdot 14$ & 21 \\
R3 & $10 \cdot 60 \pm 0 \cdot 19$ & 43 \\
R4 & $11 \cdot 15 \pm 0 \cdot 28$ & 52 \\
\hline
\end{tabular}

TICD, has the best fit to the coarsening process and to evaluate the anomalous coarsening at high volumefraction.

\section{Experimental}

Buttons of Ni-11.5 wt\% Ti alloy (C1) and pure Ni (C2) were melted in an electric-arc furnace under an argon atmosphere using pure elements (99.9\%). An assembly consisting of the specimens C1 and C2 was placed into an austenitic stainless steel holder with two screws, encapsulated into a quartz tube under an argon atmosphere and heat treated at $1473 \mathrm{~K}\left(1200{ }^{\circ} \mathrm{C}\right)$ for $28 \mathrm{~h}$ to promote the diffusion and generate the concentration gradient in the diffusion couple, subsequently, the diffusion couple was encapsulated into a quartz tube under an argon atmosphere and solution treated at $1473 \mathrm{~K}\left(1200^{\circ} \mathrm{C}\right)$ for $2 \mathrm{~h}$, followed by quenched in ice-water. Rectangular-shaped samples of around $2 \mathrm{~mm}$ in thickness were cut from diffusion couple and isothermally aged at $1023 \mathrm{~K}\left(750{ }^{\circ} \mathrm{C}\right)$ for 250, 500, 2500 and $5000 \mathrm{~min}$. The samples were prepared metallographically, and then, they were electropolished and etched at $223 \mathrm{~K}\left(-50{ }^{\circ} \mathrm{C}\right)$ using an electrolyte composed by $30 \%$ of $\mathrm{HNO}_{3}$ and $70 \%$ of methanol at 20 and $5 \mathrm{~V}$, respectively. Microstructural characterization was carried out by high resolution scanning electron microscopy (HR-SEM) using JEOL-6701F instrument and X-ray diffraction. Energy dispersive spectroscopy (EDS) was used to determine the chemical compositions along the concentration gradient. Precipitate sizes were measured from micrographs using commercial software and around 800 precipitates in each sample were considered for the measurements in order to have a representative statistical value.

\section{Results and discussion}

\subsection{Diffusion couple}

The figure 1(a) show the $\mathrm{Ni}-11.5 \mathrm{wt} \% \mathrm{Ti} / \mathrm{Ni}$ diffusion couple after diffusion heat treatment at $1473 \mathrm{~K}\left(120{ }^{\circ} \mathrm{C}\right)$ 
$R 1 / 8.62 \pm 0.28$
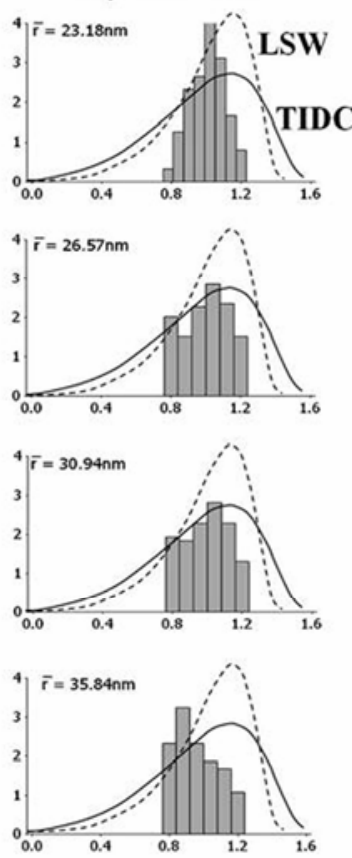

$\mathrm{R} 2 / 9.49 \pm 0.14$
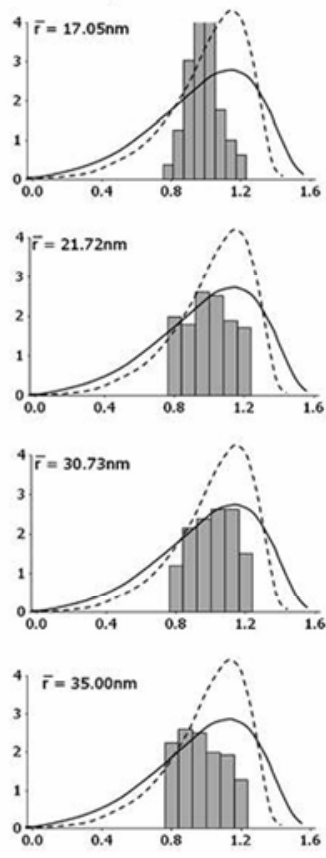

$R 3 / 10.60 \pm 0.19$
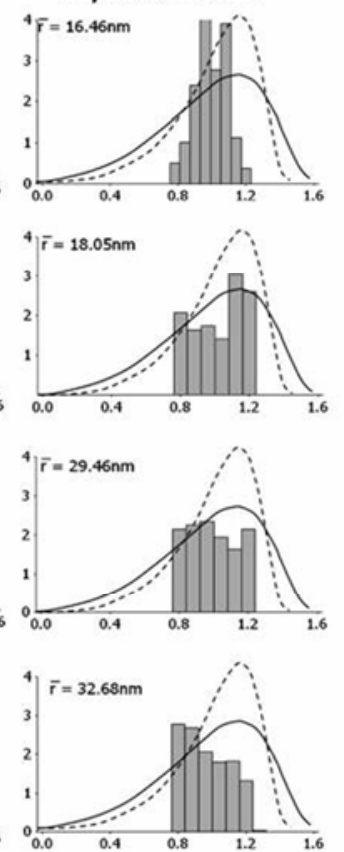

$\rho$
$R 4 / 11.15 \pm 0.28$

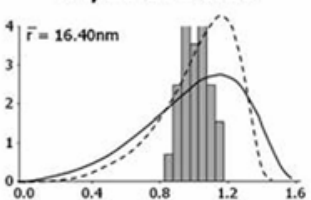

(min)

250

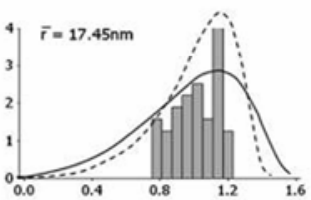

500

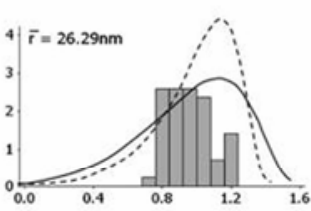

2500

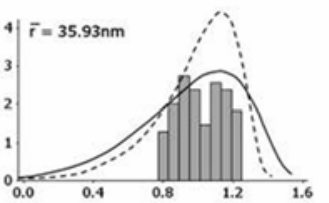

5000

Figure 3. Comparison of the experimental PSD of $\gamma^{\prime}$ precipitates obtained for R1, R2, R3 and R4 regions aged at $1023 \mathrm{~K}$ $\left(750{ }^{\circ} \mathrm{C}\right)$ with the LSW (dotted line) and TIDC (solid line) theoretical distributions.

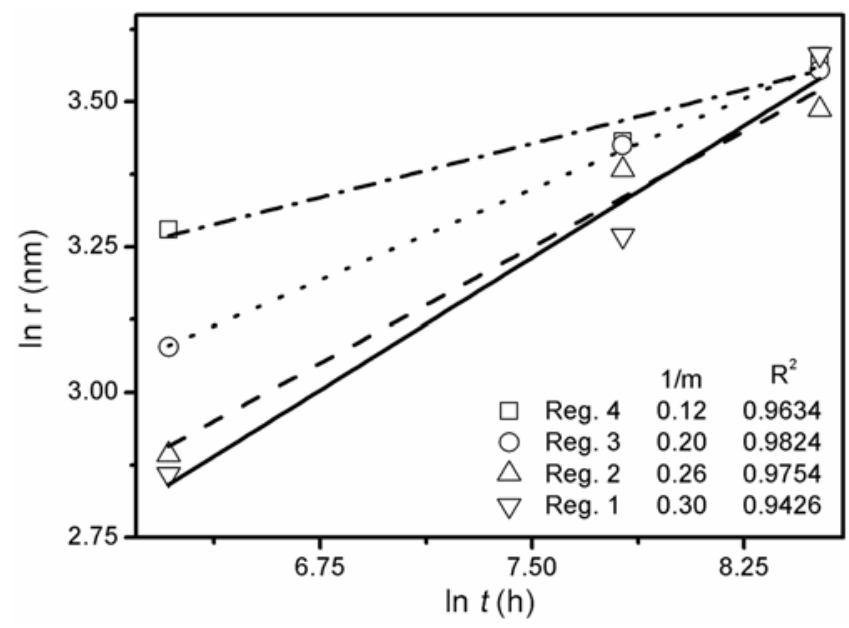

Figure 4. Plot of $\ln r$ vs $\ln t$ for R1, R2, R3 and R4 regions aged at $1023 \mathrm{~K}\left(750^{\circ} \mathrm{C}\right)$.

for $28 \mathrm{~h}$ and aging treatment at $1023 \mathrm{~K}\left(750^{\circ} \mathrm{C}\right)$ for $5000 \mathrm{~min}$. The figure 1(b) shows the concentration profile of $\mathrm{Ti}$, evidencing the existence of a concentration gradient which extends $300 \mu \mathrm{m}$ on both sides of the interface.

\subsection{Microstructural evolution}

In order to make a comparison between regions of different chemical compositions and volume-fractions, four regions into the concentration gradient were studied (R1, R2, R3 and R4), these regions show different chemical compositions and volume-fractions (determined from the coherent solvus (Rastogi and Ardell 1969)) (see table 1).

Figure 2 shows micrographs obtained by HR-SEM for regions R1, R2, R3 and R4 after aging at $1023 \mathrm{~K}$ $\left(750{ }^{\circ} \mathrm{C}\right)$ for different times. From these results, it can be seen that for all aging times, cuboidal-type precipitates with rounded corners were aligned in a certain crystallographic direction. Previous reports (Taylor and Floyd 1952, 1953; Bagariatskii and Tiapkin 1957, 1961; Bücle et al 1959; Ben Israel and Fine 1963; Sass et al 1967; Saito and Watanabe 1969; Ardell 1970; Sinclair et al 1974; Laughlin 1976; Hashimoto and Tsujimoto 1978; Grune 1988; Cerri et al 1990; Vyskocil et al 1997; Bucher et al 2002; Kompatscher et al 2003) have shown that these kind of precipitates correspond to $\gamma^{\prime}$ phase and are commonly aligned on the direction $\langle 100\rangle$ of the matrix. It was also observed $\eta$ plate-type precipitates (aging time $\geq 5000 \mathrm{~min}$ ), which grows in the (111) plane of the matrix phase (Saito and Watanabe 1969; Hashimoto and Tsujimoto 1978). It should be noted that the effect of elastic interactions between the precipitates for the regions R1 and $\mathrm{R} 4$, in the region $\mathrm{R} 1$ it was not observed a strong spatial correlation while in the region R4, it was. Since the elastic interactions between precipitates are proportional to the square lattice mismatch value, $\delta^{2}$, (where $\delta=\left(a_{\mathrm{p}}-a_{\mathrm{m}}\right) / a_{\mathrm{m}}$ and $a_{\mathrm{p}}$ and $a_{\mathrm{m}}$ are the lattice parameters of the precipitate and the matrix phase, respectively), it is 

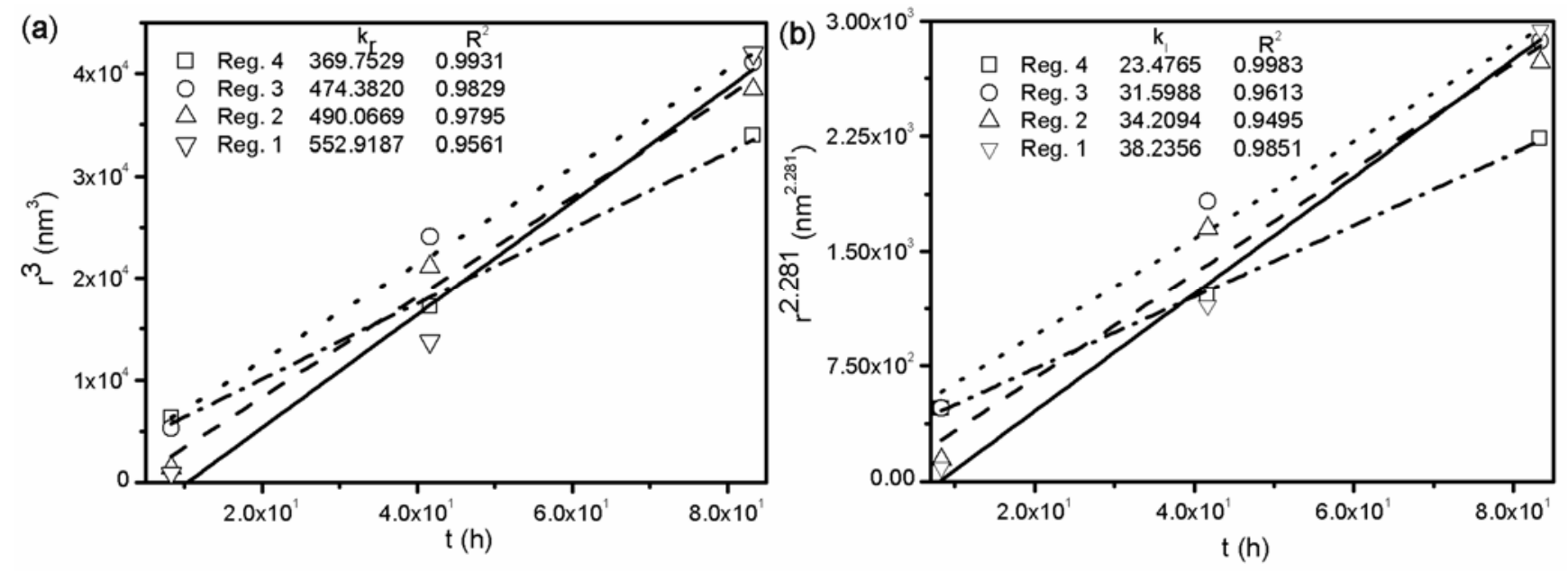

Figure 5. Plots of (a) $r^{3}$ vs $t$ (LSW theory) and (b) $r^{2 \cdot 281}$ vs $t$ (TIDC theory) for R1, R2, R3 and R4 regions aged at $1023 \mathrm{~K}$ $\left(750^{\circ} \mathrm{C}\right)$.

inferred that the magnitude of $\delta$ governs the elastic interaction energy and potentially influences the coarsening (Maheshwari and Ardell 1992; Cho and Ardell 1998; Kim and Ardell 2000, 2003, 2004). It is noteworthy that the value of $\delta$ reported for Ni-Ti alloy $(\delta=0.0085)$ is the largest of Ni-base alloys (the value of $\delta$ for the systems $\mathrm{Ni}-\mathrm{Ge}, \mathrm{Ni}-\mathrm{Al}$ and $\mathrm{Ni}-\mathrm{Si}$ is $0.0063,0.0043$ and 0.0023 , respectively) (Maheshwari and Ardell 1992; Cho and Ardell 1998; Kim and Ardell 2000, 2003, 2004).

\subsection{Coarsening kinetics of $\gamma^{\prime}$ precipitates}

3.3a Particle size distribution (PSD): The experimental PSDs are compared with the theoretical distributions, LSW and TIDC in figure 3 . The LSW theory for diffusioncontrolled coarsening leads to a highly asymmetric PSD with a cutoff near the particle radius $(\rho=1)$. The TICD PSDs are based entirely on the $n$ parameter (Ardell 2006) and is closer to theoretical PSDs of LSW theory for the interface-controlled coarsening, on the other hand the TICD PSDs are more symmetrical compared to PSDs of the LSW theory for diffusion-controlled coarsening. To determine the experimental PSDs, the equivalent radius is calculated and used as a size parameter and the probability density $\left(\rho^{2} f(\rho)\right)$ is determined with the following equation (Sequeira et al 1995):

$$
\rho^{2} f(\rho)=\frac{N_{i}(r, r+\Delta r)}{\sum N_{i}(r, r+\Delta r)} \frac{\bar{r}}{\Delta r}
$$

where $\bar{r}$ is the average radius of the precipitates and $N_{\mathrm{i}}$ $(r, r+\Delta r)$ represents the number of precipitates in a given class interval $\Delta r$. The normalized radii $(\rho)$ is defined as the ratio of $r / \bar{r}$. In general, experimental PSDs did not fit well neither LSW nor TIDC theoretical distributions. In all regions, the experimental PSDs are close to the LSW distribution for short aging times; however, for longer times the experimental PSDs are closer to TIDC distribution. The LSW distribution is independent of aging time with a volume fraction close to zero and the TIDC distribution is independent of the volume fraction and is dependent on the size of the interface, which varies according to the precipitates radius. Therefore, it can be suggested that the fit between experimental PSDs and TIDC theory at longer aging times presents significant contributions of elastic strains, because our PSDs were broad and symmetrical and generally, they can only be explained by elastic strains as has been reported previously (Ardell 1970; Lund and Voorhees 2003).

3.3b Growth exponent: The plot of $\ln r$ vs $\ln t$ obtained from R1, R2, R3 and R4 regions in the sample aged at $1023 \mathrm{~K}\left(750^{\circ} \mathrm{C}\right)$ was found to be linear for each region (figure 4). The fit to linear dependence is represented by the calculated linear regression coefficient, $R^{2}$. From these results, it is evident that in R1, for low Ti content and low volume-fraction, the value of the growth exponent $(1 / m=0 \cdot 30)$ was the highest among all the regions studied. As Ti content increases (from R1 to R4) the volume-fraction of precipitates also increases and growth exponent values decrease to a value of $1 / \mathrm{m}=0.12$ due to stronger elastic interaction in the last case. This value is close to the value obtained by Sequeira et al (1991), $(1 / m=0 \cdot 07)$, during coarsening of $\gamma^{\prime}$ large precipitates in $\mathrm{Ni}-\mathrm{Al}-\mathrm{Mo}$ system with bimodal size distribution. These authors suggested that the elastic strain fields surrounding the interface matrix/precipitate were responsible for the relatively low coarsening kinetics which was observed.

Plots of $r^{3}$ vs $t$ (LSW theory) and $r^{2 \cdot 281}$ vs $t$ (TIDC theory) are presented in figure 5 , it is seen that both $r^{3}$ and $r^{2 \cdot 281}$, exhibit an approximately linear behaviour with $t$. The $R^{2}$ value indicates good fit to the TIDC theory for 


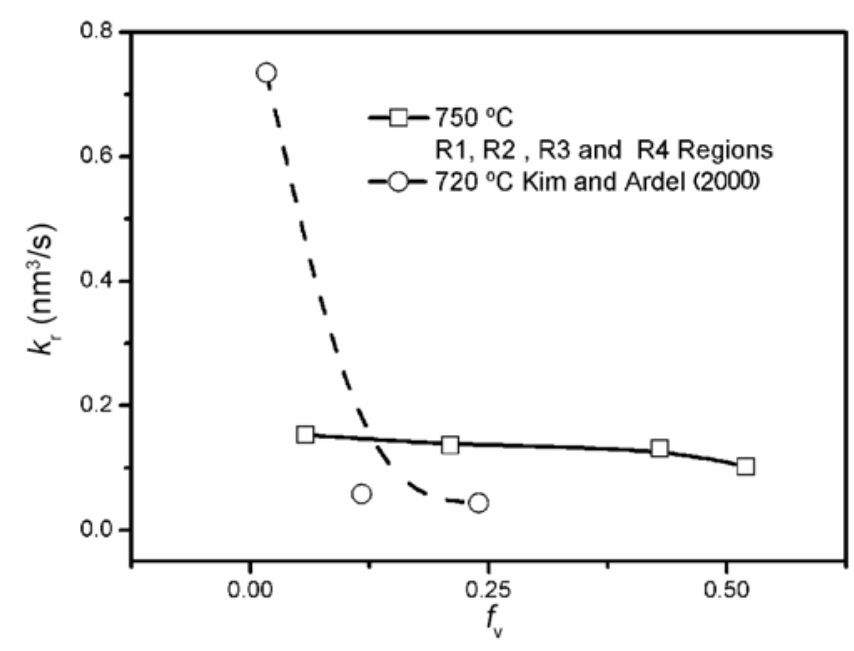

Figure 6. Plot of $k_{\mathrm{r}}\left(\mathrm{nm}^{3} / \mathrm{s}\right)$ vs $f_{\mathrm{v}}$ for $\mathrm{R} 1, \mathrm{R} 2, \mathrm{R} 3$ and $\mathrm{R} 4$ regions aged at $1023 \mathrm{~K}\left(750{ }^{\circ} \mathrm{C}\right)$. The circles are data obtained for Kim and Ardell (2000) and the squares are data obtained in this study.

regions, R1 and R4 in the figure 5(b), and to the LSW theory for the regions R2 and R3 in figure 5(a). The coarsening rate constants $\left(k_{\mathrm{r}}\right.$ and $\left.k_{\mathrm{I}}\right)$ were calculated using the slope of the linear regression analysis and it is shown that strong volume-fraction dependence, confirming by this way that elastic interactions caused a decrease in coarsening kinetics as can be seen in figure 5 .

3.3c Anomalous coarsening: The plot of $k_{\mathrm{r}}$ (for the LSW theory) obtained for each region (R1, R2, R3 and R4) vs volume-fraction $\left(f_{v}\right.$ ) (presented in figure 6 ), shows that $k_{\mathrm{r}}$ decreases slightly with increasing volume-fraction of precipitates, which suggested that anomalous coarsening is present in this system for high volume-fractions of precipitates. This kind of coarsening has been reported previously (Maheshwari and Ardell 1992; Cho and Ardell 1998; Kim and Ardell 2000, 2003, 2004) in different Ni-base alloys, but for lower volume-fraction. It is important to point out that data obtained from this study at high volume-fraction and aged at $1023 \mathrm{~K}\left(750^{\circ} \mathrm{C}\right)$ are comparable with those obtained at lower volume-fraction and aged at $993 \mathrm{~K}\left(720^{\circ} \mathrm{C}\right)(\mathrm{Kim}$ and Ardell 2000) and it was found a good correspondence between them.

\section{Conclusions}

From the results obtained, it can be concluded that during coarsening of $\gamma^{\prime}$ precipitates, the experimental coarsening kinetics did not fit well neither LSW nor TIDC theoretical models because of the presence of strong elastic interaction between precipitates.

According of experimental values of $k_{\mathrm{r}}$, which decreased slightly as precipitates volume-fraction increased that it was suggested that the presence of an anomalous coarsening for high volume-fractions. It is important to mention that this case of coarsening has been reported only for low volume-fractions of precipitates.

It can be stated that the microstructural characterization method via diffusion couple is able to characterize the coarsening stage of metastable phases for several compositions using only one sample. It greatly diminishes the number of samples and the time invested to carry out the same characterization.

\section{Acknowledgements}

The first author would like to thank CONACYT for the scholarship given and extends a special acknowledgement to the Instituto de Metalurgia (UASLP) and Instituto Politécnico Nacional (IPN) for the facilities provided for performing the experimental work.

\section{References}

Ardell A J and Ozolins V 2005 Nature Mater. 4309

Ardell A J, Kim D M and Ozolins V 2006 Z. Metallkde 97295

Ardell A J 2011 J. Mater. Sci. 464832

Ardell A J 1990 Scr. Metall. Mater. 24343

Ardell A J 2010 Acta Mater. 584325

Ardell A J 1972 Acta Metall. 2061

Ardell A J 1970 Metall. Trans. B1 525

Bagariatskii Y A and Tiapkin Y D 1961 Soviet Phys. Cryst. 5 841

Bagariatskii Y A and Tiapkin Y D 1957 Soviet Phys. Cryst. 2 414

Ben Israel D H and Fine M E 1963 Acta Metall. 111051

Brailsford A D and Wynblatt P 1979 Acta Metall. 27489

Bucher R, Demè B, Heinrich H, Kohlbrecher J, Kompatscher M, Kostorz G, Schneider J M, Schönfeld B and Zolliker M 2002 Mater. Sci. Eng. A324 77

Bücle C, Genty B and Manenc J 1959 Rev. Metall. 56247

Cerri A, Schönfeld B and Kostorz G 1990 Phys. Rev. B42 958

Cho J H and Ardell A J 1998 Acta Mater. 465907

Contreras-Piedras E, Dorantes-Rosales H J, López-Hirata V M, Hernández-Santiago F, González-Velázquez J L and LópezMonrroy F I 2012 Mater. Sci. Eng. A558 366

Davies C K L, Nash P and Stevens R N 1980 Acta Metall. 28179

Grune R 1988 Acta Metall. 362797

Hashimoto K and Tsujimoto T 1978 Trans. JIM 1977

Kim D M and Ardell A J 2004 Metall. Mater. Trans. A35 3063

Kim D M and Ardell A J 2003 Acta Mater. 514073

Kim D M and Ardell A J 2000 Scr. Mater. 43381

Kompatscher M, Schönfeld B, Heinrich H and Kostorz G 2003 Acta Mater. $\mathbf{5 1} 165$

Laughlin D E 1976 Acta Metall. 2453

Lifshitz I M and Slyozov V V 1961 J. Phys. Chem. Solids 1935

Lund A C and Voorhees P W 2003 Philos. Mag. 831719

Maheshwari A and Ardell A J 1992 Acta Metall. Mater. 40 2661

Marqusee J A and Rose J 1984 J. Chem. Phys. 80536

Miyazaki T 2012 Progr. Mater. Sci. 571010 
Rastogi P K and Ardell A J 1969 Acta Metall. 17595

Saito K and Watanabe R 1969 Japan J. Appl. Phys. 814

Sass S L, Mur T and Cohen J B 1967 Phil. Mag. 16680

Sequeira A D, Calderon H A, Kostorz G and Pedersen J S 1995 Acta Metall. Mater. 433441

Sinclair R, Leake J A and Ralph B 1974 Phys. Status Solidi (a) 26285

Taylor A and Floyd R W 1952-53 J. Inst. Metals 8125
Tokuyama M and Kawasaki K 1984 Physica A 123386

Tsumaraya K and Miyata Y 1983 Acta Metall. 31437

Voorhees P W and Glicksman M E 1984a Acta Metall. 32 2001

Voorhees P W and Glicksman M E 1984b Acta Metall. 322013

Vyskocil P, Pedersen J S, Kostorz G and Schönfeld B 1997 Acta Mater. 453311

Wagner C 1961 Z. Elektrochem. 65581 